\title{
Antiinflammatory Influences of $\alpha$-MSH Molecules: Central Neurogenic and Peripheral Actions
}

\author{
A. Macaluso, ${ }^{1}$ D. McCoy, ${ }^{1}$ G. Ceriani, ${ }^{2}$ T. Watanabe, ${ }^{1}$ J. Biltz, ${ }^{1}$ A. Catania, ${ }^{2}$ and J. M. Lipton' \\ ${ }^{1}$ Departments of Physiology and Anesthesiology, University of Texas Southwestern Medical Center at Dallas, Dallas, \\ Texas 75235-9040 and ${ }^{2}$ First Medical Clinic, University of Milan, Milan, Italy 20122
}

$\alpha$-Melanocyte-stimulating hormone $\left(\alpha-\mathrm{MSH}_{1-13}\right)$ and its $\mathrm{COOH}$ terminal tripeptide $\alpha$ - $\mathrm{MSH}_{11-13}$ (Lys Pro Val) inhibit inflammation when administered systemically. Recent evidence indicates that $\alpha-\mathrm{MSH}_{1-13}$ can likewise inhibit inflammation in the skin solely via an action within the brain. Because of the potential importance of this discovery to understanding the control of inflammation and because $\alpha$-MSH molecules might be useful for treatment of inflammation, experiments were performed to learn more about the mechanisms of action of these peptides. In tests on inflammation induced in the mouse ear by intradermal injections of recombinant human interleukin-1 $\beta, \alpha-\mathrm{MSH}_{1-13}$ administered intracerebroventricularly effectively reduced inflammation. This effect of centrally administered $\alpha-\mathrm{MSH}_{1-13}$ was inhibited by systemic injection of the nonspecific $\beta$-adrenergic receptor blocker propranolol and by administration of a specific $\beta_{2}$-adrenergic receptor antagonist; the effect was not altered by blockade of cholinergic, $\alpha$-adrenergic, or $\beta_{1}$-adrenergic receptors. In mice with inflammation induced in a hind paw and with the spinal cord transected, the antiinflammatory effect of centrally administered $\alpha-\mathrm{MSH}_{1-13}$ was prevented, indicating that intact descending neuronal pathways are required for the antiinflammatory influence of the central peptide. Systemic injection of $\alpha-\mathrm{MSH}_{1-13}$ in animals with spinal cord transection had a smaller and later antiinflammatory effect, which suggests that the molecule also has an action, albeit lesser, in the periphery. However, $\alpha$ - $\mathbf{M S H}_{11-13}$ injected intraperitoneally had marked antiinflammatory activity in animals with spinal cord transection. The combined evidence indicates that $\alpha-\mathbf{M S H}_{1}$ ${ }_{13}$ has both central and peripheral sites of action in modulation of inflammation; the central effects of $\alpha-\mathrm{MSH}_{1-13}$ are mediated by pathways that involve peripheral $\beta_{2}$-adrenergic receptors; the antiinflammatory/antipyretic message sequence of $\alpha-\mathrm{MSH}_{1-13}, \alpha-\mathrm{MSH}_{11-13}$, has potent antiinflammatory activity when given systemically, activity that does not require intact spinal cord pathways.

[Key words: $\alpha$-melanocyte-stimulating hormone ( $\alpha-M S H)$, inflammation, $\alpha-M_{1,-13}$, central mediation of antiinflammatory actions of $\alpha-M S H$, peripheral antiinflammatory actions of $\alpha$-MSH, mouse, $\beta_{2}$-adrenergic blockade, spinal cord transection, interleukin-1-induced inflammation]

Received May 12, 1993; revised Oct. 4, 1993; accepted Oct. 14, 1993.

This research was supported by NIH Grant NS10046 from the National Institute of Neurological Diseases and Stroke, by NATO Collaborative Research Grant 2000467, and a University of Milan fellowship (G.C.).

Correspondence should be addressed to J. M. Lipton, Ph.D., UT Southwestern Medical Center, Dallas, TX 75235-9040.

Copyright (c) 1994 Society for Neuroscience $0270-6474 / 94 / 142377-06 \$ 05.00 / 0$
Inflammation, a localized response to tissue injury, and disorders characterized by inflammation are difficult problems in clinical medicine. This difficulty stems in large part from incomplete understanding of inflammatory processes and their regulation. Recent development of knowledge of the role of central nervous and neuroendocrine systems in host responses (Besedovsky and del Rey, 1992; Goetzl and Sreedharan, 1992) has provided a new view of the capacity of neuronal and soluble mediators in these systems to influence inflammation. One of these mediators is the endogenous neuropeptide $\alpha$-melanocytestimulating hormone $\left(\alpha-\mathrm{MSH}_{1-13}\right)$, which is believed to modulate host reactions to challenge by inhibiting the actions of cytokines (Lipton, 1990; Catania and Lipton, 1993). This neuropeptide, which occurs in the pituitary, brain, skin, and other body regions (Eberle, 1988), is usually derived from the precursor proopiomelanocortin. Binding sites for the peptide are widespread (Tatro and Reichlin, 1987), and $\alpha$-MSH receptors have recently been characterized and cloned (Mountjoy et al., 1992). This peptide, which shares the 1-13 amino acid sequence with adrenocorticotropic hormone, has remarkable antiinflammatory and antipyretic properties. In brief, $\alpha-\mathrm{MSH}_{1-13}$ reduces fever when given centrally or systemically even in very small doses (Murphy et al., 1983). The fact that $\alpha$-MSH inhibits fever when given systemically indicates that the molecule reaches the brain; true antipyretic agents reduce fever via CNS actions. There is also direct evidence of penetration of the peptide into the brain (Wilson, 1988), albeit in small amounts. During fever there is pulsatile release of the molecule from septal sites (Bell and Lipton, 1987), sites where $\alpha$-MSH injections cause antipyresis (Glyn-Ballinger et al., 1983), and blockade of endogenous central $\alpha$-MSH with antiserum augments the febrile response to pyrogen (Shih et al., 1986). The COOH-terminal tripeptide of $\alpha-\mathrm{MSH}_{1-13}$ is the primary amino acid sequence required for this antipyretic action (Richards and Lipton, 1984). These and related observations suggest that this molecule and the antipyretic tripeptide $\alpha-\mathrm{MSH}_{11-13}$ are important modulators of fever and related acute phase reactions (Lipton, 1990; Lipton and Catania, 1992; Catania and Lipton, 1993). These molecules were also found to have potent antiinflammatory activity when administered systemically (Lipton, 1988, 1989; Hiltz and Lipton, 1989, 1990; Catania and Lipton, 1993; Hiltz et al., 1992). Recent observations indicate that, in addition to its action within the brain to reduce fever, $\alpha$-MSH can also act centrally to inhibit inflammation in the skin (Lipton et al., 1991). This observation opens a new view of control of inflammation, and it raises the possibility of development of antiinflammatory agents that are based on the peptide and that specifically target the CNS. The first step toward this possibility is to improve un- 


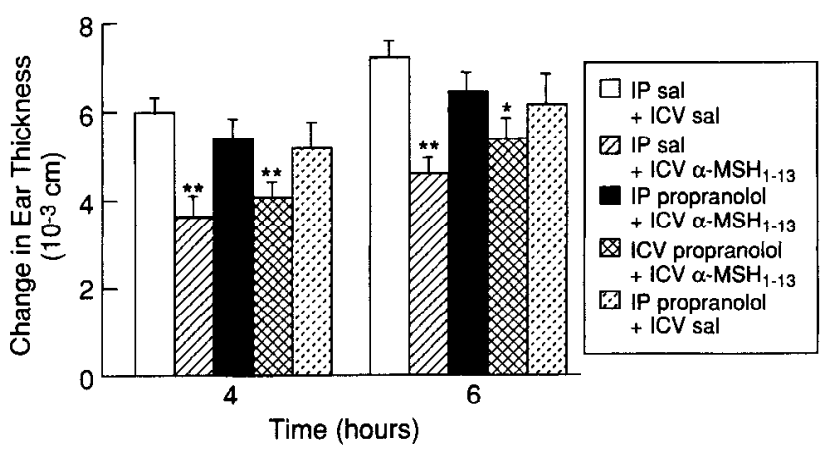

Figure 1. Edema caused by intradermal injection of human recombinant IL-1 $\beta$ in the mouse ear was inhibited by intracerebroventricular injection of $\alpha-\mathrm{MSH}_{1-13}$ given at the time of cytokine injection. This antiinflammatory action of centrally administered $\alpha-\mathrm{MSH}_{1-13}$ was inhibited by propranolol given intraperitoneally but not when the drug was injected intracerebroventricularly. Saline-alone scores indicate the edema induced solely by injection of vehicle into the ear. Each score in this and following figures represents a mean $( \pm$ SEM) value based on abservations made on 10-25 mice. Each mouse was used for only one experiment. ${ }^{*}, P<0.05 ;{ }^{* *}, P<0.01$; compared with control values, Tukey's test, two-tail (applies to Figs. 1-6).

derstanding of the site (central, peripheral) and mechanism of antiinflammatory action of $\alpha$-MSH molecules.

The major aim of this research was to examine the effects of pharmacological blockade or surgical interruption of neural pathways on antiinflammatory activity of centrally administered $\alpha$-MSH. To test the effect of pharmacological blockade of neural transmission, certain neurotransmitter receptor antagonists were administered together with central $\alpha$-MSH in mice in which inflammation was induced in the ear by interleukin$1 \beta$ (IL-1 $\beta$ ). Any interference with the antiinflammatory influence of centrally injected $\alpha$-MSH would disclose which, if any, neurotransmitters are required for transmission of antiinflammaiory signal induced by central $\alpha$-MSH to peripheral sites. In related experiments, the antiinflammatory effects of central or peripheral injections of $\alpha-\mathrm{MSH}_{1-13}$, or of systemic injection of $\alpha-\mathrm{MSH}_{11-13}$, were tested in mice with transected spinal cords in which inflammation was induced in a hind paw. Results of these tests could answer several questions: (1) Is the central antiinflammatory signal induced by $\alpha$-MSH conveyed through pathways that utilize specific neurotransmitters? (2) Are patent descending neural pathways required for the antiinflammatory action of the peptide, or can the influence be mediated by other, perhaps circulating, factors? (3) Does $\alpha$-MSH act solely within the brain or can it also act in the periphery when isolated from the influence of cerebral tissue?

\section{Materials and Methods}

The experiments were approved by the local Internal Review Board for Animal Research. Female BALB/c mice (Simonsen Laboratorics, Gilroy, $\mathrm{CA}), 7-8$ weeks old, were housed at $23-25^{\circ} \mathrm{C}$ in groups not exceeding five animals per cage $[28 \mathrm{~cm}(\mathrm{~L}) \times 18 \mathrm{~cm}(\mathrm{~W}) \times 13 \mathrm{~cm}(\mathrm{H})]$. Before the experiments they were acclimatized for not less than 1 week before experimentation to standard lighting and temperature conditions with food and water freely available.

Experiments on $\alpha-M S H$ administration and pharmacological blockade in mouse ear edema. Mice were anesthetized with $10 \%$ pentobarbital sodium solution $(1 \mathrm{mg} /$ mouse, $50 \mathrm{mg} / \mathrm{ml}$, Nembutal sodium solution; Abbott Laboratories, North Chicago, IL). Baseline ear thickness measurements were taken with a spring-loaded micrometer (Swiss Precision Instruments, Los Angeles, CA). Ear thickness was expressed as cubic centimeters and was measured at least twice at each time point. The

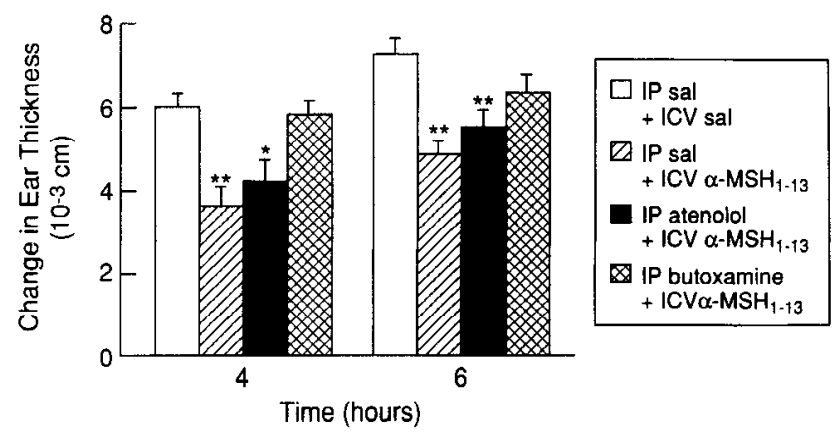

Figure 2. Inhibition of the antiinflammatory actions of centrally administered $\alpha-\mathrm{MSH}_{1-13}$ by the $\beta_{2}$-adrenergic antagonist butoxamine. Atenolol, a $\beta_{1}$-adrenergic antagonist, failed to inhibit the antiinflammatory actions of the peptide.

avcrage thickncss of unstimulated ears was $26.82 \mathrm{~cm}^{-3}$. Inflammation was induced by injecting $20 \mu \mathrm{l}$ of recombinant human IL-1 $\beta(1500 \mathrm{U}$; Genzyme, Cambridge, MA) directly in to the skin (intradermally) of one ear of each mouse using a 28 gauge needle (Hiltz et al., 1992). Measures of ear thickness were repeated 4 and $6 \mathrm{hr}$ later, while the mice were under sodium pentobarbital anesthesia. Edema was assessed by subtracting baseline measures from 4 and $6 \mathrm{hr}$ readings for each animal. $\alpha-\mathrm{MSH}_{1-13}(1663.9 \mathrm{gm} / \mathrm{mol}$; Peninsula Laboratories, Belmont, CA) or $\alpha-\mathrm{MSH}_{1 \mathrm{l}-13}(383.48 \mathrm{gm} / \mathrm{mol}$; Peninsula Laboratories) dissolved in saline was injected intracerebroventricularly $(20 \mu \mathrm{l})$ using procedures described previously (Lipton et al., 1991; Lipton and Catania, 1993).

Several agents were administered at the time of ear challenge to pharmacologically block certain receptors: atropine (Sigma Chemical Co.; $150 \mu \mathrm{g}$, i.p.), a muscarinic receptor blocker that acts on autonomic endorgan receptors, was chosen because of links between inflammation and modulation of pain and the finding that muscarinic agonists increase pain threshold (Hartvig et al., 1989); phentolamine (Sigma; $150 \mu \mathrm{g}$, i.p.), an agent that competes for occupancy of $\alpha$-adrenergic receptors; proprarolol (Sigma; $150 \mu \mathrm{g}$, i.p.; $30 \mu \mathrm{g}$, i.c.v.), a nonspecific competitive antagonist for $\beta$-adrenergic receptors. After positive effects were observed with propranolol, selective antagonists of $\beta$-adrenergic receptors were tested: atenolol (Sigma; $150 \mu \mathrm{g}$, i.p.), a $\beta_{1}$-adrenergic receptor antagonist; butoxamine (Sigma; $150 \mu \mathrm{g}$, i.p.), a $\beta_{2}$-adrenergic receptor blocker

Experiments on central and peripheral administration of $\alpha-M S H$ and spinal cord transection in mouse paw edema. Because surgical dissection of trigeminal structures that innervate the ear of the mouse is very difficult, tests to learn whether descending neural pathways are essential to the antiinflammatory activity of centrally administered $\alpha$-MSH peptides were performed in mice with inflammation induced in a hind paw. In these experiments, each animal was anesthetized with pentobarbital sodium solution as above. Baseline foot pad thickness of both hind paws was measured with a spring-loaded micrometer (Swiss Precision Instruments, Los Angeles, CA). Paw thickness was expressed in units of $10^{-3} \mathrm{~cm}$; average thickness of unstimulated paws was $171.5 \times 10^{-3} \mathrm{~cm}$ across shipments of animals. Kappa carrageenan (Sigma) dissolved in saline $(0.05 \%, 20 \mu 1)$ was injected ( 28 gauge allergy test syringe) into one footpad, and saline $(20 \mu \mathrm{l})$ was injected into the other. For the analyses, the increase in thickness of the control saline-injected paw of each animal was subtracted from that of the carrageenan-injected paw, to eliminate the influence of mechanical injury and volume of the injected fluid. To be certain that mice with severed spinal cords can react to antiinflammatory agents, prednisolone $(2.5 \mathrm{mg} / \mathrm{mouse}$, i.p. $)$ was administered to 10 mice with spinal transection and inflammation induced by carrageenan. Treatment with the locally acting steroid reduced swelling up to 29\% (average, relative to saline controls) at $4.5 \mathrm{hr}$ after carrageenan. This finding indicates that spinal transection in these mice does not result in stasis of inflammation that is unalterable as a result of vasodilatation, hypotension, or other hemodynamic changes.

Pilot studies indicated that interruption of the spinal cord of the mouse by surgical exposure, visualization, and severing with a scalpel blade resulted in marked bleeding, morbidity, and death in a substantial number of animals. However, a standardized crushing of lumbar vertebrae with a hemostat (Kelly) was effective in severing the cord; no deaths were caused by this treatment. In the experiments proper, all animals 


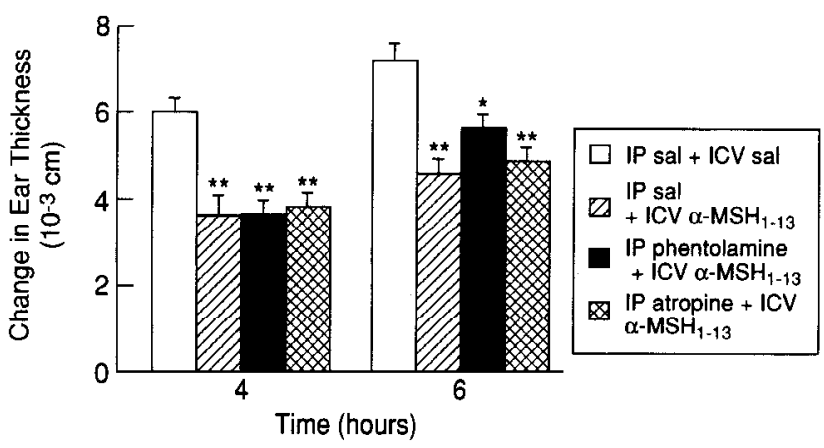

Figure 3. Phentolamine and atropine did not inhibit the antiinflammatory action of centrally administered $\alpha-\mathrm{MSH}_{1-13}$.

were tested after cord section when the anesthesia had worn off: none showed behavioral or motor responses to pinching of the hind feet with a hemostat; all had complete paralysis of the hind limbs. Data of animals that did not meet these criteria were excluded from the analyses. The experiments were limited to $4.5 \mathrm{hr}$ to reduce problems of bowel and bladder dysfunction. Immediately after the $4.5 \mathrm{hr}$ measurements all mice were killed with an overdose of sodium pentobarbital.

Statistical analysis. Because of the size of the experiments and the requirement for several shipments of animals over time, several experiments were performed, each with complete treatment and control groups drawn from the same shipment of mice. Omnibus analysis of variance techniques (Dynastat, Washington, DC) were used to test overall differences among group means. Tukey's protected $t$ test was used to compare individual means. Probability values of $<0.05$ were considered significant.

\section{Results}

Antiinflammatory effect of centrally administered $\alpha-M S H$ and the influence of blockade of neurotransmitter receptors

In tests of the contribution of certain neurotransmitter receptors to the antiinflammatory effect of centrally administered $\alpha-\mathrm{MSH}_{1}$. ${ }_{13}$, there were differences in means in the experiments with propranolol $[F(4,52)=4.17, p<0.005]$. This nonspecific $\beta$-blocker $(150 \mu \mathrm{g})$ had no effect on the antiinflammatory influence of $\alpha-\mathrm{MSH}_{1-13}$ when injected centrally (the inhibition by $\alpha$-MSH was $36 \%$ and $32 \%$ at 4 and $6 \mathrm{hr}$, respectively), whereas $300 \mu \mathrm{g}$ of the agent administered intraperitoneally did inhibit the antiinflammatory response to this peptide (Fig. 1). This indicates that blockade of peripheral $\beta$-receptors inhibits the antiinflammatory influence of central $\alpha$-MSH. In subsequent tests to differentiate the role of specific $\beta$-adrenergic receptors in the antiinflammatory effect of centrally administered $\alpha$-MSH, intraperitoneal injection of the $\beta_{1}$-blocker did not inhibit the effect of the peptide significantly, whereas the $\beta_{2}$-receptor antagonist butoxamine did (Fig. 2). This result indicates that $\beta_{2}$-receptor activity in the periphery is essential to the antiinflammatory action of central $\alpha$-MSH. Blockade of $\alpha$-adrenergic receptors with phentolamine, and of cholinergic (muscarinic) receptors with atropine, did not alter the antiinflammatory effect of $\alpha-\mathrm{MSH}_{1-13}$ (Fig. 3).

\section{Effects of central and peripheral administration of $\alpha$-MSH peptides on inflammation in mice with spinal cord transection}

An omnibus ANOVA of the data on central $\alpha$-MSH and inflammation in intact and cord-transected mice yielded a significant difference in treatment means $[F(3,228)=12.3, p<$ $0.0001]$ and a significant $(p<0.01)$ treatment/time interaction. Central administration of $\alpha-\mathrm{MSH}_{1-13}$ in intact mice markedly inhibited inflammation induced in the hind paw (Fig. 4), con-

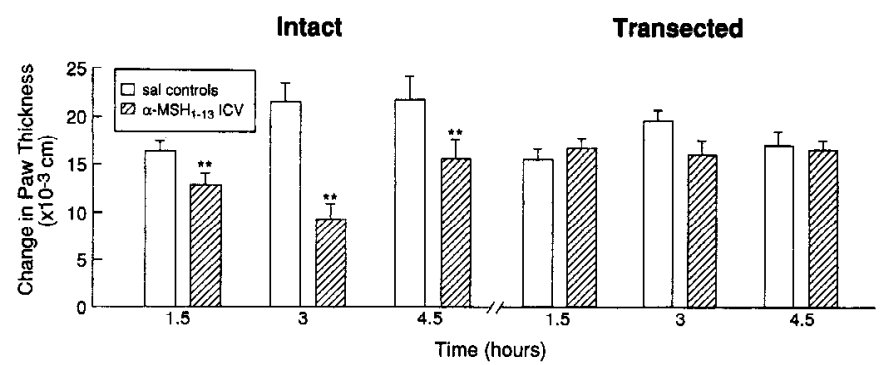

Figure 4. Whereas the edema caused by injection of $\kappa$-carrageenan in one hindpaw was reduced in intact mice given the peptide intracerebroventricularly, transection of the spinal cord prevented the antiinflammatory action of centrally administered $\alpha-\mathrm{MSH}_{1-13}$.

sistent with findings in other models (Lipton et al., 1991; Watanabe et al., 1993). The greatest effect was at $3 \mathrm{hr}(57 \% \mathrm{inhi}-$ bition); inhibition was less at $4.5 \mathrm{hr}(29 \%)$, a result that conforms with previous estimates of the duration of action of this molecule. On the other hand, spinal cord transection prevented development of a significant antiinflammatory effect of centrally administered $\alpha-\mathrm{MSH}_{1,13}$ (Fig. 4). Our previous experiments on recombinant human IL- $1 \beta$ indicate that both centrally and peripherally administered $\alpha-\mathrm{MSH}_{1-13}$ can inhibit inflammation (Lipton et al., 1991). Systemic injection of this peptide did inhibit inflammation in additional experiments (Fig. 5). Transection of the spinal cord completely eliminated the early antiinflammatory effect of $\alpha-\mathrm{MSH}_{1-13}$ given intraperitoneally; there was a significant, although smaller, inhibitory effect later in the period. To learn if the influence of systemically injected tripeptide requires it to act on the brain to induce descending inhibitory signals, this molecule was administered intraperitoneally to mice with spinal cord transection (Fig. 6). The tripeptide had a marked inhibitory effect on inflammation. This finding indicates that $\alpha$ - $\mathrm{MSH}_{11-13}$ can exert an antiinflammatory action in the periphery, an action that does not require descending inhibitory signals from the brain.

\section{Discussion}

The data show that the antiinflammatory influence of centrally administered $\alpha$-MSH requires intact descending neural pathways for its expression. In addition, evidence obtained in the experiments on pharmacologic blockadc of ncural transmission indicates that descending antiinflammatory impulses generated by $\alpha$-MSH within the brain require $\beta_{2}$-adrenergic receptors for expression of the antiinflammatory influence in the periphery.

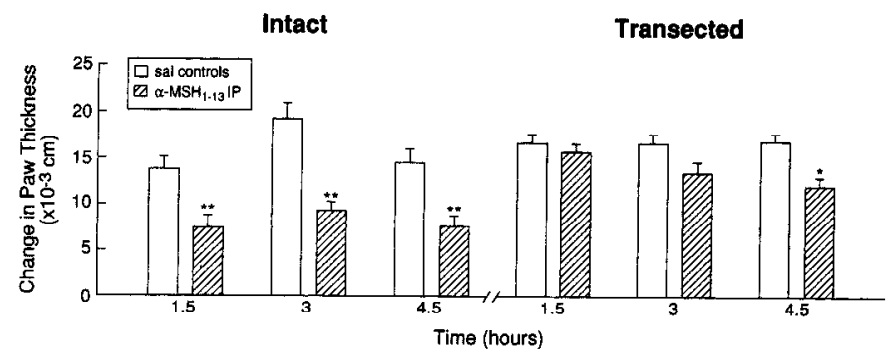

Figure 5. Spinal cord interruption inhibited the antiinflammatory effect of systemically administered $\alpha-\mathrm{MSH}_{\mathrm{i}-13}$ measured at 1.5 and $3 \mathrm{hr}$ after injection of $k$-carrageenan in the hind paw. However, by $4.5 \mathrm{hr}$ the systemically administered peptide significantly reduced inflammation. 


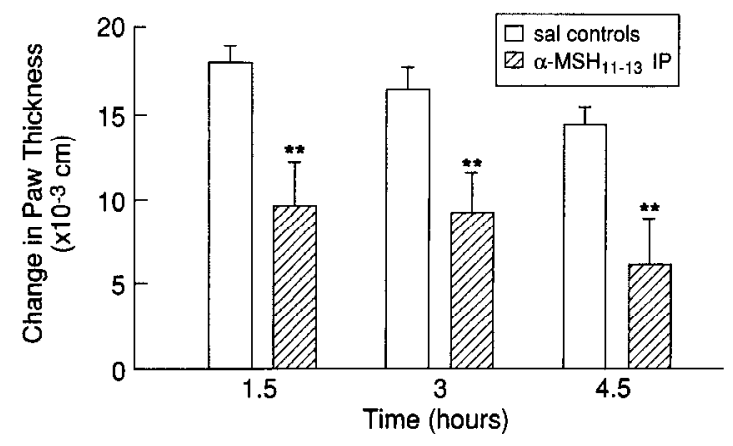

Figure $6 . \quad$ Marked antiinflammatory effect of intraperitoneal injection of the tripeptide $\alpha-\mathrm{MSH}_{1-13}$ in mice with spinal cord transection.

However, $\alpha$-MSH molecules do not act solely within the brain to inhibit inflammation in the periphery because systemic injections of peptides in mice with spinal cord transection reduced inflammation. These observations provide new perspectives of the mechanism of antiinflammatory action of $\alpha$-MSH molecules.

The results confirm, in two additional models, our previous observation (Lipton et al., 1991) that central administration of $\alpha$-MSH inhibits inflammation in the periphery. In the original observations on mice with inflammation induced by picryl chloride, $\alpha-\mathrm{MSH}_{1-13}$ injected centrally reduced the edema when given in doses that were ineffective when administered intraperitoneally $(0.1-10 \mu \mathrm{g})$. This result could not be traced to an increase in circulating corticosterone, an established inhibitor of inflammation; blockade of dopamine receptors that are important to $\alpha$-MSH release and actions likewise had no effect. In the present research, inflammation induced in the mouse ear by a cytokine and in the mouse paw by a classic stimulator of the inflammatory reaction was inhibited by central $\alpha$-MSH. These observations indicate that an antiinflammatory influence in the periphery can be induced by activation of central $\alpha$-MSH receptors.

How does this occur? Two approaches were taken to answer this question: (1) pharmacological blockade to determine if autonomic receptors are essential to the antiinflammatory effect in the ear (trigeminal system), and (2) transection of spinal pathways in mice with edema in the hind paw to ascertain if direct neuronal connections are essential to the antiinflammatory effect. In the mouse ear edema model the primary new finding was that the antiinflammatory effect of centrally administered $\alpha$-MSH is inhibited by blockade of peripheral $\beta$-adrenergic receptors whereas treatment with muscarinic or $\alpha$-adrenergic receptor blockers is ineffective. These observations suggest that descending impulses generated by $\alpha$-MSH actions within the brain induce signals in autonomic pathways that involve $\beta_{2}$ receptors and modulate inflammation. The failure of central propranolol to influence the antiinflammatory effect of central $\alpha$-MSH in combination with the observations that intraperitoneal injection of both propranolol and butoxamine did inhibit the effect of the peptide indicates that $\beta_{2}$-receptors in the periphery are vital to the effect. Although blockade of the antiinflammatory influence of centrally administered $\alpha-\mathrm{MSH}_{1-13}$ with a peripherally administered adrenergic antagonist provides a new view of the mechanism of action of the peptide, $\beta$-adrenergic agonists have long been known to exert antiinflammatory influences (Green, 1972; Maling et al., 1974). As examples, a $\beta_{2}$-adrenoreceptor agonist inhibited bradykinin-induced leakage from postcapillary venules (Svensjo et al., 1977), and propranolol reversed the inhibitory effect of isoproterenol on skin reactions induced by histamine, $5-\mathrm{HT}$, and leukotriene $\mathrm{C}_{4}$ (Inagaki et al., 1989). Such findings suggest that $\beta_{2}$-adrencrgic reccptors are generally important to modulation of inflammation. It is clear that there is a large population of such receptors in epidermal membrane homogenates from human skin (Steinkraus et al., 1992). It may be that these receptors have a role in local modulation of inflammation, whether the antiinflammatory agent is $\alpha$-MSH given centrally or another agent administered systemically.

In mice with spinal transection we found that the antiinflammatory action of centrally administered $\alpha$-MSH was completely eliminated, suggesting that descending pathways in the spinal cord are essential to the antiinflammatory effect. This observation, along with the lack of increase in circulating corticosterone after central $\alpha$-MSH administration (Lipton et al., 1991), appears to rule out an essential circulating mediator of the antiinflammatory influence of centrally injected $\alpha$-MSH. It may be that the central $\alpha$-MSH-induced modulation of inflammation in the periphery occurs via inhibition of release of proinflammatory agents (e.g., substance P) from afferent nerve terminals. This idea, patterned from evidence of descending pain modulation pathways (Beeson and Chaouch, 1982), is favored by observations that in such pathways agents released from sensory nerve fibers that cause pain in injured tissue are likewise potent proinflammatory agents. It is reasonable to suppose that descending signals that restrict release of such chemicals and thus modulate pain may simultaneously modulate inflammation through similar or perhaps the same actions. The modulatory effect on fever induced by endogenous and administered $\alpha$-MSH is well established (Lipton, 1990; Lipton and Catania, 1992; Catania and Lipton, 1993). Modulation of other host responses to challenge, such as increased circulating C-reactive protein, has also been observed after central administration of the peptide (Dao et al., 1988). The present and previous findings (see Catania and Lipton, 1993) converge to emphasize the importance of central actions of $\alpha$-MSH to the modulation of multiple host responses to challenge. The results are also evidence of a more general phenomenon: CNS/neuroendocrine modulation of host responses.

The present evidence and our previous research on salicylates (Catania ct al., 1991) clcarly indicatc that the CNS can exert antiinflammatory as well as antipyretic influences. It also appears that inflammation in the periphery can be enhanced by actions of soluble mediators within the brain. We recently noted that endogenous pyrogen, believed to include a mixture of cytokines, can act within the brain to promote inflammation (Dulaney et al., 1992); one clinical implication of this result is that central inflammation, or simply central actions of cytokines, can promote inflammation in affected sites in the periphery. It thus appears that the signals induced in the brain by $\alpha$-MSH and endogenous pyrogen are capable of anti- and proinflammatory activity, respectively. In line with this idea, it has been noted that intracerebroventricular injection of bradykinin can augment carrageenan-induced paw edema (Bhattacharya et al., 1988). Likewise, activation of central cholinergic receptors (Bhattacharya et al., 1991) or central administration of prostaglandin (Bhattacharya et al., 1989) can promote inflammation. The CNS/peripheral inflammation relationships appear to be bidirectional in that peripheral inflammation can likewise induce changes in the CNS. For example, it is clear that there are 
changes in excitatory and inhibitory amino acids in dorsal horn extracellular fluid during experimental arthritis (Sorkin et al., 1992); in related studies, substance $P$ and calcitonin gene-related peptide in the dorsal horn decreased in experimentally induced arthritis. C-fos expression in rat lumbar cord is altered during the development of adjuvant-induced arthritis (Abbadie and Beeson, 1992). There is increased content and transport of substance $\mathbf{P}$ and calcitonin gene-related peptide in sensory nerves innervating inflamed tissue (Donnerer et al., 1992). These observations combine to support the idea that there are bidirectional interactions between the CNS and inflammation in the periphery.

A small, delayed antiinflammatory effect was induced by intraperitoneal injection of $\alpha$-MSH in mice with spinal transection. This observation suggests that, in addition to its central action to reduce inflammation and fever, $\alpha$-MSH can act in the periphery, perhaps directly on inflamed tissue. Results with the antiinflammatory/antipyretic amino acid sequence $\alpha-\mathrm{MSH}_{11-13}$ in the same model indicate that this molecule had a particularly strong influence on inflammation when given intrapcritoncally. This observation suggests that the tripeptide can act directly in the periphery to reduce inflammation without induction of central antiinflammatory signals that descend in the spinal cord. Indeed, the results also suggest that the smaller molecule is even more active in the periphery in the mouse with transected spinal cord than $\alpha-\mathrm{MSH}_{1-13}$. The smaller, late antiinflammatory effect of $\alpha-\mathrm{MSH}_{1-13}$ given intraperitoneally in mice with transected cords may indicate metabolism of the injected peptide over time and subsequent action of a $\mathrm{COOH}$-terminal fragment that contains the tripeptide sequence. The question of an action of the peptides directly within sites of inflammation must remain open; it may be that the peptides can act on neurons in the spinal cord, or upon peripheral nerves or other tissues below the transection.

However, the finding that the peptides can act in the periphery raiscs qucstions about their mechanism of action with regard to modulation of specific factors involved in peripheral inflammation. In addition to possible inhibition of release of proinflammatory mediators directly within injured tissue, two other possibilities arise from previous research on $\alpha$-MSH: antagonism of cytokine activity and inhibition of neutrophil migration. $\alpha$-MSH molecules reduce effects of cytokines that mediate host responses, including inflammation. In recent research we noted that $\alpha$-MSH inhibits inflammation caused by IL-1, IL-6, and tumor necrosis factor $\alpha$ (TNF $\alpha$ ), injected intradermally in mice (Hiltz et al., 1992). This observation and many others on the anti-cytokine activity of the peptide, extending from countering their effects on thymocyte proliferation (Cannon et al., 1986), on immunosuppression and natural killer cell activity (Weiss et al., 1991) (see Catania and Lipton, 1993, for review), support the idea that the peptide inhibits actions of cytokines. Research by Mason and van Epps (1989) showed that intraperitoneal injection of $\alpha$-MSH in mice blocks migration of neutrophils into subcutaneous sponges treated with IL-1, TNF, or complement $\mathrm{C} 5 \mathrm{a}$, which suggests that the peptide inhibits chemotaxis induced by cytokine signals. The latter observation may reflect a direct action on neutrophils, or it may simply be another example of the anti-cytokine activity of $\alpha$-MSH. Cytokines are important mcdiators of inflammation; neutrophil migration is a hallmark of the inflammatory response and these known influences of $\alpha$-MSH on them may be adequate to explain the antiinflammatory action of $\alpha-\mathrm{MSH}$ in the periphery. The precise nature of the peripheral actions of $\alpha$-MSH molecules in bringing about their antiinflammatory effect at the cellular level is of considerable interest; similarly, development of knowledge of the specific cellular changes, both within the CNS and in the periphery, that underlie the antiinflammatory action of central $\alpha$-MSH is essential to a more complete understanding of this powerful influence of the peptide.

In summary, the results confirm that $\alpha$-MSH can act within the brain to inhibit inflammation in the periphery. In the case of the ear edema model it appears that $\beta_{2}$ receptors in the periphery are important to the antiinflammatory effect of centrally administered $\alpha$-MSH; $\beta_{1}$-adrenergic, $\alpha$-adrenergic, and cholinergic (muscarinic) receptors do not appear to be essential to this effect. The spinal cord transection studies point out the essential nature of patent spinal pathways to the antiinflammatory effect of central $\alpha-\mathrm{MSH}_{1-13}$. However, there was evidence of direct peripheral antiinflammatory action of $\alpha-\mathrm{MSH}_{1-13}$ administered intraperitoneally in animals with transected spinal cords and, particularly, of a potent effect of the tripeptide $\alpha-\mathrm{MSH}_{11-13}$. The observation that $\alpha$-MSH molecules inhibit inflammation via actions within the CNS, and perhaps more directly within the periphery, is novel; it suggests a consistent functional role of these ancient molecules in the modulation of host responses to challenge.

\section{References}

Abbadie C, Beeson JM (1992) c-fos expression in rat lumbar spinal cord during the development of adjuvant-induced arthritis. Neuroscience 48:985-993.

Beeson JM, Chaouch A (1987) peripheral and spinal mechanisms of nociception. Physiol Rev 67:67-186.

Bell RC, Lipton JM (1987) Pulsatile release of the antipyretic neuropeptide $\alpha$-MSH from the septum of the rabbit during fever. Am J Physiol 252:R1152-R1157.

Besedovsky HO, del Rey A (1992) Immune-neuroendocrine circuits: integrative role of cytokines. Front Neuroendocrinol 13:61-94.

Bhattacharya SK, Mohan Rao PJR, Das N, Das Gupta G (1988) Intracerebroventricularly administered bradykinin augments carrageenan-induced paw oedema in rats. J Pharm Pharmacol 40:367-369.

Bhattacharya SK, Mohan Rao PJR, Das Gupta G (1989) Effect of centrally administered prostaglandin $\mathrm{D}_{2}$ and some prostaglandin synthesis inhibitors on carrageenan-induced paw oedema in rats. J Pharm Pharmacol 41:569-571.

Bhattacharya SK, Sen AP, Das Gupta G, Seth K, Seth PK (1991) Central muscarinic receptor subtypes and carrageenin-induced paw oedema in rats. Res Exp Med 191:65-76.

Cannon JG, Tatro JB, Reichlin S, Dinarello CA (1986) Melanocyte stimulating hormone inhibits immunostimulatory and inflammatory actions of interleukin 1. J Immunol 137:2232-2236.

Catania A, Lipton JM (1993) a-Melanocyte-stimulating hormone peptides in host responses: from basic evidence to human research. Ann NY Acad Sci 680:608-625.

Catania A, Arnold J, Macaluso A, Hiltz ME, Lipton JM (1991) Inhibition of acute inflammation in the periphery by central action of salicylates. Proc Natl Acad Sci USA 88:8544-8547.

Dao TK, Bell RC, Feng J, Jameson DM, Lipton JM (1988) C-Reactive protein, leukocytes, and fever after central IL-1 and $\alpha$-MSH in aged rabbits. Am J Physiol 254:R401-R409.

Donnerer J, Schuligoi R, Stein C (1992) Increased content and transport of substance $P$ and calcitonin gene-related peptide in sensory nerves innervating inflamed tissue: evidence for a regulatory function of nerve growth factor in vivo. Neuroscience 29:693-698.

Dulaney R, Macaluso A, Woerner J, Hiltz M, Catania A, Lipton JM (1992) Changes in peripheral inflammation induced by CNS actions of an $\alpha$-MSH analog and of endogenous pyrogen. Prog Neuroendocrinimmunology 5:179-186.

Eberle A (1988) The melanotropins. Basel: Karger.

Glyn-Ballinger JR, Bernardini GL, Lipton JM (1983) $\alpha$-MSH injected into the septal region reduces fever in rabbits. Peptides 4:199-203. 
Goetzl EJ, Sreedharan SP (1992) Mediators of communication and adaptation in the neuroendocrine and immune systems. FASEB $\mathbf{J}$ 6:2646.

Green KL (1972) The antiinflammatory effect of catecholamines in the peritoneal cavity and hind paw of the mouse. Br J Pharmacol 45: 322-332.

Hartvig P, Gillberg PG, Gordh T Jr, Post C (1989) Cholinergic mechanisms in pain and analgesia. Trends Pharmacol Sci [Suppl] 75-79.

Hiltz ME, Lipton JM (1989) Antiinflammatory activity of a COOHterminal fragment of the neuropeptide $\alpha-\mathrm{MSH}$. FASEB J 3:22822284.

Hiltz ME, Lipton JM (1990) Alpha-MSH peptides inhibit acute inflammation and contact hypersensitivity. Peptides 11:972-982.

Hiltz ME, Catania A, Lipton JM (1991) Antiinflammatory activity of $\alpha$-MSH(11-13) analogs: influences of alterations in stereochemistry. Peptides 12:767-771.

Hiltz ME, Catania A, Lipton JM (1992) $\alpha$-MSH peptides inhibit acute inflammation induced in mice by rIL- $1 \mathrm{~b}, \mathrm{rIL}-6, \mathrm{rTNF} \alpha$ and endogenous pyrogen but not that caused by $\mathrm{LTB}_{4}, \mathrm{PAF}$ and rlL- 8 . Cytokine 4:320-328.

Inagaki N, Miura T, Daikoku M, Nagai H, Koda A (1989) Inhibitory effects of $\beta$-adrenergic stimulants on increased vascular permeability caused by passive cutaneous anaphylaxis, allergic mediators, and mediator releasers in rats. Pharmacology 39:19-27.

Lipton JM (1988) MSH in CNS control of fever and its influence on inflammation/immune responses. In: The melanotropic peptides, Vol 2 (Hadlcy ME, ed), pp 97-113. Boca Raton, FL: CRC.

Lipton JM (1989) Neuropeptide alpha-melanocyte stimulating hormone in control of fever, the acute phase response and inflammation. In: Neuroimmune networks: physiology and diseases (Goetal EJ, Spector NH, eds), pp 243-250. New York: Liss.

Lipton JM (1990) Modulation of host defense by the neuropeptide $\alpha$-MSH. Yale J Biol Med 63:173-182.

Lipton JM, Catania A (1992) $\alpha$-MSH peptides modulate fever and inflammation. In: Neuro-immunology of fever (Bartfai T, Ottoson D, eds), pp 123-136. New York: Pergamon.

Lipton JM, Catania A (1993) Pyrogenic and inflammatory actions of cytokines and their modulation by neuropeptides: techniques and interpretations. In: Methods in neuroscience (DeSouza EB, ed), pp 61-79. Orlando, FL: Academic.

Lipton JM, Macaluso A, Hiltz ME, Catania A (1991) Central administration of the peptide $\alpha$-MSH inhibits inflammation in the skin. Peptides 12:795-798.
Maling HM, Webster ME, Williams MA, Saul W, Anderson W Jr (1974) Inflammation induced by histamine, serotonin, bradykinin and compound 48/80 in the rat: antagonist and mechanisms of action. J Pharmacol Exp Ther 191:300-310.

Mason MJ, Van Epps D (1989) Modulation of IL-1, tumor necrosis factor, and C5a-mediated murine neutrophil migration by $\alpha$-melanocyte-stimulating hormone. J Immunol 142:1646-1651.

Mountjoy KG, Robbins LS, Mortrud MT, Cone RD (1992) The cloning of a family of genes that encode the melanocortin receptors. Science 257:1248-1251.

Murphy MT, Richards DB, Lipton JM (1983) Antipyretic potency of centrally administered $\alpha$-melanocyte stimulating hormone. Science 221:192-193.

Richards DB, Lipton JM (1984) Effect of $\alpha$-MSH(11-13) (lysine-proline-valine) on fever in the rabbit. Peptides 5:815-817.

Shih ST, Khorram O, Lipton JM, McCann SM (1986) Central administration of $\alpha-\mathrm{MSH}$ antiserum augments fever in the rabbit. Am J Physiol 250:R803-R806.

Sorkin LS, Westlund KN, Sluka KA, Dougherty PM, Willis WD (1992) Neural changes in acute arthritis in monkeys. IV. Time-course of amino acid release into the lumbar dorsal horn. Brain Res Rev 17: $39-50$.

Steinkraus V, Steinfath M, Korner C, Mensing H (1992) Binding of beta-adrenergic receptors in human skin. J Invest Dermatol 98:475480.

Svensjo E, Persson CGA, Rutili G (1977) Inhibition of bradykinininduced macromolecular leakage from post-capillary venules by a $\beta_{2}$ adrenoreceptor stimulant, terbutaline. Acta Physiol Scand 101:514516.

Tatro JB, Reichlin S (1987) Spccific receptors for $\alpha$-melanocyte stimulating hormone are widely distributed in the tissues of rodents Endocrinology 121:1900-1907.

Watanabe T, Hiltz ME, Catania A, Lipton JM (1993) Inhibition of Il-1 $\beta$ induced peripheral inflammation by peripheral and central administration of analogs of the neuropeptide $\alpha$-MSH. Brain Res Bull 32:311-314.

Weiss JM, Sundar SK, Cierpial MA, Ritchie JC (1991) Effects of interleukin- 1 infused into brain are antagonized by $\alpha$-MSH in a dosedependent manner. Eur J Pharmacol 192:177-179.

Wilson JF (1988) Low permeability of the blood-brain barrier to nanomolar concentrations of immunoreactive alpha-melanotropin. Psychopharmacology 96:262-266. 